\title{
Physicochemical stability of ternary admixtures of butorphanol, ketamine, and droperidol in polyolefin bags for patient-controlled analgesia use
}

This article was published in the following Dove Press journal:

Drug Design, Development and Therapy

24 November 2016

Number of times this article has been viewed

\section{Baoxia Fang' \\ Linhai Wang ${ }^{2}$ \\ Junfeng $\mathrm{Gu}^{3}$ \\ Fuchao Chen' \\ Xiao-ya Shi'}

'Department of Pharmacy, Dongfeng Hospital, ${ }^{2}$ Department of Pharmacy, ${ }^{3}$ Department of Anesthesiology, Renmin Hospital, Hubei University of Medicine, Hubei, People's Republic of China
Correspondence: Xiao-ya Shi Department of Pharmacy, Dongfeng Hospital, Hubei University of Medicine, No 16 Daling Road, Shiyan, Hubei, 442008, People's Republic of China Email dfyyshixiaoya@sina.com
Background: Delivery of drug admixtures by intravenous patient-controlled analgesia is a common practice for the management of postoperative pain; however, analytical confirmation of the compatibility and stability of butorphanol tartrate, ketamine hydrochloride, and droperidol combined in ternary admixtures is not available.

Methods: Butorphanol tartrate, ketamine hydrochloride, and droperidol have been examined for compatibility and stability when combined with $0.9 \%$ sodium chloride injection stored at $4{ }^{\circ} \mathrm{C}$ and $25^{\circ} \mathrm{C}$ with light protection for a total of 14 days. Concentrations were $0.067 \mathrm{mg} / \mathrm{mL}, 1.33 \mathrm{mg} / \mathrm{mL}$, and $0.033 \mathrm{mg} / \mathrm{mL}$ for butorphanol tartrate, ketamine hydrochloride, and droperidol, respectively. Drug concentrations were determined using high-performance liquid chromatographic analysis. Results: All three drugs were very stable $(>97 \%)$ at $4{ }^{\circ} \mathrm{C}$ and $25^{\circ} \mathrm{C}$ for 14 days. The ternary admixtures were initially clear and colorless throughout the observation period, and the $\mathrm{pH}$ value did not change significantly.

Conclusion: The results confirm that the ternary admixture of butorphanol tartrate $0.067 \mathrm{mg} / \mathrm{mL}$, ketamine hydrochloride $1.33 \mathrm{mg} / \mathrm{mL}$, and droperidol $0.033 \mathrm{mg} / \mathrm{mL}$ in $0.9 \%$ sodium chloride injection were stable for 14 days when stored in polyolefin bags at $4{ }^{\circ} \mathrm{C}$ and $25^{\circ} \mathrm{C}$ and protected from light.

Keywords: analgesia, patient-controlled analgesia, drug stability, butorphanol, ketamine, droperidol, HPLC

\section{Introduction}

Butorphanol tartrate is a mixed agonist-antagonist opioid with strong $\kappa$-receptor agonist and weak $\mu$-receptor antagonist activity. It is commonly used for the management of cancer, postoperative, gynecologic, and obstetric pain. As with other opioid analgesics, patient-controlled analgesia (PCA) butorphanol tartrate is associated with troublesome side effects such as nausea and/or vomiting, somnolence, and dizziness. ${ }^{1,2}$ Droperidol is a dopamine $\mathrm{D}_{2}$ receptor antagonist that has been widely used for the prevention and treatment of postoperative nausea and vomiting (PONV) and analgesic-induced PONV during PCA over several decades. ${ }^{3}$ Ketamine, a noncompetitive N-methyl-D-aspartate antagonist, exerts at subanesthetic doses and can prevent the development of central sensitization and opioid resistance. Hence, subanesthetic dose of ketamine is used as an adjuvant to opioids PCA for postoperative pain control. ${ }^{4,5}$

Recently, a triple-component solution containing butorphanol tartrate, ketamine hydrochloride, and droperidol with PCA was reported to give satisfactory analgesic effects and decrease the incidence of nausea and vomiting in patients after upper limbs surgery. ${ }^{6}$ In addition, the ternary analgesic admixture has sometimes been used for 
postoperative patients in our institution. However, the ternary analgesic mixtures are not available commercially for clinical use, and they must be prepared in the hospital pharmacy departments under aseptic conditions. Mixing two or more drugs together in infusion solutions via intravenous PCA can lead to physical and/or chemical changes, which may result in variations in therapeutic properties and unknown side effects. $^{7}$ In the literature, the compatibility of butorphanol tartrate with ketamine hydrochloride or droperidol in binary admixtures was studied, ${ }^{8,9}$ but from daily practice there is a need for additional research on the compatibility of these drugs in ternary admixtures. Thus, the objective of the current study was to determine the compatibility and stability of the ternary admixture of butorphanol tartrate, ketamine hydrochloride, and droperidol in $0.9 \%$ sodium chloride injection when stored in polyolefin bags at $4^{\circ} \mathrm{C}$ and $25^{\circ} \mathrm{C}$ for 14 days.

\section{Methods}

\section{Materials and reagents}

The reference standards of butorphanol tartrate, ketamine hydrochloride, and droperidol were procured from the National Institute for Control of Pharmaceutical and Biological Products (Beijing, People's Republic of China) and stored at $4^{\circ} \mathrm{C}$. Ampoules of butorphanol tartrate $(1 \mathrm{mg} / 1 \mathrm{~mL}$, batch number 14120204) were obtained from Jiangsu Hengrui Medicine Co., Ltd. (Lianyungang, People's Republic of China). Ketamine hydrochloride injection $(100 \mathrm{mg} / 2 \mathrm{~mL}$, batch number 150102T) was purchased from Shyndec Pharmaceutical Co., Ltd (Shanghai, People's Republic of China). Ampoules of droperidol (5 mg/2 mL, batch number 150415) were supplied by Xudong Pharmaceutical Co., Ltd (Shanghai, People's Republic of China). Sodium chloride for injection, $0.9 \%$ that was used to prepare the sample mixtures, was obtained from Kelun Pharmaceutical Co., Ltd. (Sichuan, People's Republic of China, batch number A150826). High-performance liquid chromatography (HPLC)-grade acetonitrile was purchased from Fisher Scientific International (St Louis, MO, USA). Potassium dihydrogen phosphate $\mathrm{KH}_{2} \mathrm{PO}_{4}$, triethylamine, and phosphoric acid of AR Grade were obtained from Jinlu Chemical Ltd. (Shanghai, People's Republic of China). Ultrapure water was purified using a Milli-Q system (Millipore, Bedford, MA, USA).

\section{HPLC instrumentation and chromatographic conditions}

A UltiMate ${ }^{\circledR} 3000$ Standard LC systems (Dionex, Sunnyvale, CA, USA) composed of an UltiMate 3000 quaternary gradient pump, an ASI-100 auto sampler, a TCC-100 column oven, a DAD-3000RS detector equipped with Chromeleon ${ }^{\circledR}$ software (Dionex, Voisins-le- Bretonneux, France) was used. HPLC separations were performed on a phenomenex $\mathrm{C}_{18}$ column $(4.6 \times 150 \mathrm{~mm}, 5 \mu \mathrm{m})$. The mobile phase contained a mixture of $0.05 \mathrm{~mol} / \mathrm{L} \mathrm{KH}_{2} \mathrm{PO}_{4}$, acetonitrile, and triethylamine in the ratio 70:30:1 (v/v). The $\mathrm{pH}$ was adjusted to 4.0 using diluted phosphoric acid, and the mobile phase was filtered through a $0.22 \mu \mathrm{m}$ filter. The flow rate of the mobile phase was kept at $1.0 \mathrm{~mL} / \mathrm{min}$. The selected detection wavelengths for droperidol, ketamine hydrochloride, and butorphanol tartrate were 246,268 , and $280 \mathrm{~nm}$, respectively. The assay was performed at $30^{\circ} \mathrm{C}$ and injection volume was $20 \mu \mathrm{L}$.

\section{Validation of the HPLC method}

The HPLC method was validated for linearity, accuracy, precision, and stability of the three analytes. Linearity was demonstrated by running the standard solutions at six different concentrations and three replicates over the range of $2.5-50,25-750$, and $1-50 \mu \mathrm{g} / \mathrm{mL}$ of butorphanol tartrate, ketamine hydrochloride, and droperidol, respectively. Calibration curve was performed by plotting peak areas against drug concentrations. The coefficient of determination $\left(\mathrm{r}^{2}\right)$ was calculated. Replicate analyses $(n=5)$ of quality control samples at three concentration levels $(5.0,12.5$, and $25.0 \mu \mathrm{g} / \mathrm{mL}$ for butorphanol tartrate; $125.0,250.0$, and $500.0 \mu \mathrm{g} / \mathrm{mL}$ for ketamine hydrochloride; $5.0,7.5$, and $12.5 \mu \mathrm{g} / \mathrm{mL}$ for droperidol) were used for determining the precision and accuracy of the assay. Precision was calculated as the coefficient of relative standard deviation (\%) within a single run (intraday), among different runs (interday). The accuracy was calculated by means of the recovery value. The analytical methods for each of the drugs were validated as stable indicated by accelerated degradation. The sample solutions of butorphanol tartrate with ketamine hydrochloride and droperidol in $0.9 \%$ sodium chloride injection were degraded with $0.1 \mathrm{~mol} / \mathrm{L}$ sodium hydroxide (acidified), $0.1 \mathrm{~mol} / \mathrm{L}$ sodium hydroxide (alkaline degraded), and 3\% hydrogen peroxide (oxidized) for $5 \mathrm{~h}$ at $60^{\circ} \mathrm{C}$. The chromatogram obtained for the degraded preparation was compared with a chromatogram obtained from the standard curve to confirm separation of the parent molecule from its degradation products.

\section{Preparation of ternary admixtures and storage conditions}

The ternary mixtures of butorphanol tartrate, ketamine hydrochloride, and droperidol were freshly prepared under aseptic conditions in laminar flow hoods and kept in the 
dark at refrigeration $\left(4^{\circ} \mathrm{C} \pm 0.5^{\circ} \mathrm{C}\right)$ and at room temperature $\left(25^{\circ} \mathrm{C} \pm 0.5^{\circ} \mathrm{C}\right)$. In order to mimic the concentration relevant to clinical practice, ${ }^{6} 10 \mathrm{mg}$ butorphanol tartrate injection $(10 \mathrm{~mL}), 200 \mathrm{mg}$ ketamine hydrochloride injection $(4 \mathrm{~mL})$, and $5 \mathrm{mg}$ droperidol injection $(2 \mathrm{~mL})$ were transferred to a $150 \mathrm{~mL}$ polyolefin bags and filled with normal saline.

\section{Compatibility and stability studies of the ternary admixtures}

The compatibility and stability studies were conducted in triplicate for each storage condition. Samples of $5 \mathrm{~mL}$ were removed from each ternary admixture for the analyses of appearance, $\mathrm{pH}$, and drug concentration at predetermined times $(0,1,3,5,7,10$, and 14 days). At the specified times, color change, cloudiness, and precipitation were evaluated against light and dark backgrounds. Moreover, the $\mathrm{pH}$ of each solution was also determined at each analysis by using a PHS-3C pH meter (Leici Instrument Co., Shanghai, People's Republic of China). On the day of analysis, samples were allowed to reach room temperature and diluted 1:4 in water before injection into a HPLC system. Samples from each bags were analyzed in triplicate (total $\mathrm{N}=3$ ).

\section{Data analysis}

Mean values and standard deviations (SDs) were calculated for samples analyzed in triplicate. The starting concentrations of butorphanol tartrate, ketamine hydrochloride, and droperidol were defined as $100 \%$. The concentration of each drug, obtained on each day of the study (remaining drug), was expressed as a percentage of its initial concentration in the respective mixture. The admixtures were considered chemically stable if they retained $90 \%$ of the initial concentrations. The changes with time of the concentrations of the drugs in solution were analyzed using one factor analysis of variance. A $P$-value of $<0.05$ was considered to be significant.

\section{Results HPLC method validation}

The HPLC method was established in the current work for simultaneously determining butorphanol tartrate, ketamine hydrochloride, and droperidol in PCA mixture samples. Under the current chromatographic conditions, these three drugs were satisfactorily separated. A typical chromatogram of standard solution containing each of the components listed earlier is shown in Figure 1. The average retention time for ketamine hydrochloride, butorphanol tartrate, and droperidol was found to be $4.5,6.0$, and $10.7 \mathrm{~min}$, respectively. Under extreme conditions (strong acidic, basic, and oxidation

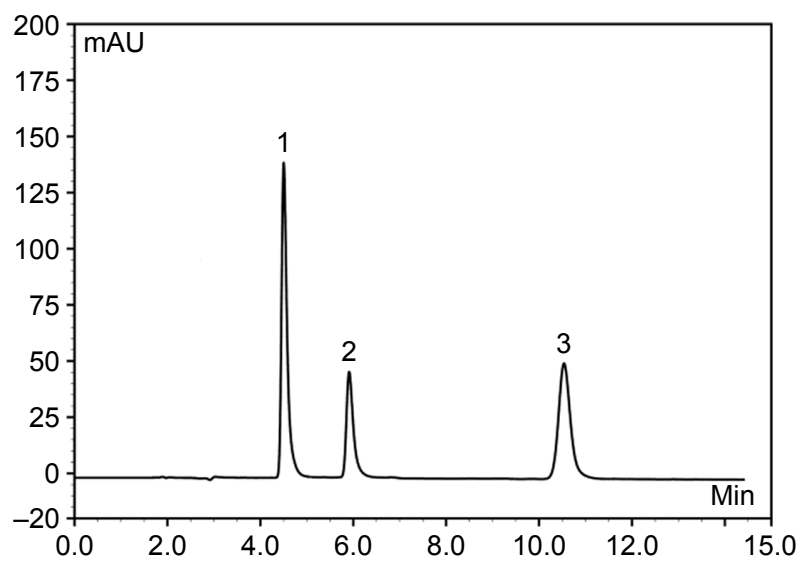

Figure I Chromatograms of standard drug mixture samples obtained after $20 \mu \mathrm{L}$ direct injection. Peak I: ketamine hydrochloride; peak 2: butorphanol tartrate; peak 3: droperidol.

Abbreviation: $\mathrm{mAU}$, milli absorbance unit.

solutions), these three drugs were found to be stable with $<3 \%$ decomposition compounds and baseline separated from all analytes. The linearity of butorphanol tartrate, ketamine hydrochloride, and droperidol was in the range of 2.5-50.0, 25.0-75.0, and 1.0-50.0 $\mu \mathrm{g} / \mathrm{mL}$, respectively, with correlation coefficient $>0.999$. Table 1 summarizes the results of the intraday and interday precision and the accuracy of the assay method for the three analytes. The data showed that the proposed method provides acceptable accuracy, intraday, and interday for quality control of butorphanol tartrate, ketamine hydrochloride, and droperidol in the PCA samples.

\section{Compatibility and stability of the ternary admixtures}

The chemical stability results of ternary mixtures of butorphanol tartrate, ketamine hydrochloride, and droperidol in normal saline for PCA administration are presented in Tables 2-3. As indicated in Tables 2-3, the results obtained through this study showed that there is no loss in butorphanol tartrate, ketamine hydrochloride, and droperidol concentrations at both storage temperatures. At the end of the study period (14 days), the percentages of the three drugs remaining in the admixtures were $>97 \%$. For the physical stability results, the ternary mixtures remained clear and colorless for the duration of the study at $4{ }^{\circ} \mathrm{C}$ or $25^{\circ} \mathrm{C}$. Moreover, the $\mathrm{pH}$ of the ternary mixtures was slightly acidic with $\mathrm{pH}$ values ranging from 4.7 to 4.8 during the 14-day experiment.

\section{Discussion}

Postoperative patients commonly suffer from several symptoms at the same time, such as pain, nausea/vomiting, and anxiety. Multimodal analgesia is a common practice in the 
Table I Validation of HPLC method

\begin{tabular}{|c|c|c|c|c|}
\hline \multirow[t]{2}{*}{ Compound } & \multirow{2}{*}{$\begin{array}{l}\text { Measured } \\
\text { concentrations }(\mu \mathrm{g} / \mathrm{mL})\end{array}$} & \multirow[t]{2}{*}{ Accuracy (\%) } & \multicolumn{2}{|c|}{ Precision RSD (\%) } \\
\hline & & & Intraday & Interday \\
\hline \multirow[t]{3}{*}{ Butorphanol tartrate } & 5.0 & 98.1 & 0.6 & 1.4 \\
\hline & 12.5 & 101.8 & 0.9 & 2.1 \\
\hline & 25.0 & 100.9 & 1.2 & 1.7 \\
\hline \multirow[t]{3}{*}{ Ketamine hydrochloride } & 125.0 & 101.2 & 0.3 & 0.8 \\
\hline & 250.0 & 100.5 & 0.8 & 1.2 \\
\hline & 500.0 & 102.1 & 1.5 & 2.5 \\
\hline \multirow[t]{3}{*}{ Droperidol } & 5.0 & 101.7 & 0.5 & 0.9 \\
\hline & 7.5 & 100.3 & 0.7 & 1.6 \\
\hline & 12.5 & 98.5 & 0.4 & I.I \\
\hline
\end{tabular}

Abbreviations: HPLC, high-performance liquid chromatography; RSD, relative standard deviation.

control of postoperative pain and symptoms. The former involves the use of a combination of analgesics, with the aim of providing superior pain relief and reducing the incidence of side effects associated with the component drugs. ${ }^{9-11}$ Combination of butorphanol tartrate, ketamine hydrochloride, and droperidol in solutions for PCA infusion is now accepted for postoperative pain control, but information on the compatibility and stability of the ternary mixtures for PCA is unavailable. Therefore, the aim of this study was to address this issue.

As noted previously, stability of butorphanol tartrate, ketamine hydrochloride, and droperidol single or combined with other drugs in solution has been previously established. Butorphanol tartrate, ketamine hydrochloride, and droperidol at room temperature have been reported to be stable for at least 1 week in $5 \%$ dextrose injection or $0.9 \%$ sodium chloride injection. ${ }^{12-17}$ Combination of butorphanol tartrate with other drugs in solution has resulted in variable results. It is stable when combined with ketamine hydrochloride, ${ }^{8}$ droperidol, ${ }^{9}$ tramadol hydrochloride, ${ }^{18}$ fentanyl citrate, ${ }^{18}$ granisetron hydrochloride, ${ }^{19}$ tropisetron hydrochloride, ${ }^{20}$ perphenazine, ${ }^{21}$ and ropivacaine hydrochloride, ${ }^{22}$ but unstable with lornoxicam ${ }^{23}$ and lansoprazole ${ }^{24}$ in $0.9 \%$ sodium chloride injection. As for ketamine hydrochloride, the stability and compatibility test of ketamine hydrochloride combined with other drugs in infusion solutions has been widely demonstrated that ketamine hydrochloride is a highly stable drug. It has been reported to be stable with tramadol hydrochloride, ${ }^{25}$ morphine hydrochloride, ${ }^{26-29}$ hydromorphone, ${ }^{30,31}$ fentanyl citrate, ${ }^{32}$ dexamethasone sodium phosphate, ${ }^{33}$ clonidine hydrochloride, ${ }^{34}$ midazolam hydrochloride, ${ }^{34}$ lormetazepam, ${ }^{34}$ and propofol ${ }^{35}$ in binary admixtures. Regarding droperidol, the solubility showed strong $\mathrm{pH}$ dependence (pKa was 7.64), which is stable in acid solution and may cause drug precipitation or crystallization in alkaline solution. Droperidol has been shown to be physicochemically compatible with butorphanol tartrate, ${ }^{9}$ ondansetron hydrochloride, ${ }^{36}$ tramadol hydrochloride, ${ }^{37}$ morphine sulfate, ${ }^{38}$ fentanyl citrate, ${ }^{39}$ ketamine hydrochloride, ${ }^{39}$ and piritramide ${ }^{40}$ under normal conditions. In contrast, droperidol was demonstrated to be incompatible when combined with allopurinol sodium, amphotericin B cholesteryl sulfate complex, fluorouracil, furosemide, lansoprazole, methotrexate sodium, and pemetrexed disodium..$^{24,41-43}$

In the present study, the ternary mixtures were acidic, with $\mathrm{pH}$ ranging from 4.7 to 4.8 . No precipitation was observed in the ternary mixtures at both the temperatures. The concentrations of the three drugs in the ternary mixtures at day 14 were $>97 \%$ of their initial concentration. In addition, no changes were observed in the chromatograms after butorphanol tartrate was combined with ketamine hydrochloride and droperidol in the infusion solutions. Based on

Table 2 Stability of butorphanol tartrate, ketamine hydrochloride, and droperidol in $0.9 \%$ sodium chloride stored in polyolefin bags at $4^{\circ} \mathrm{C}$

\begin{tabular}{|c|c|c|c|c|c|c|c|}
\hline \multirow[t]{2}{*}{ Drug } & \multirow{2}{*}{$\begin{array}{l}\text { Initial } \\
\text { concentration }(\mu \mathrm{g} / \mathrm{mL})^{\mathrm{a}}\end{array}$} & \multicolumn{6}{|c|}{ Percentage initial concentration remaining $($ mean \pm SD) } \\
\hline & & Day I & Day 3 & Day 5 & Day 7 & Day 10 & Day 14 \\
\hline Butorphanol tartrate & $66.9 \pm 0.95$ & $100.2 \pm 1.2$ & $102.5 \pm 2.4$ & $98.6 \pm 1.3$ & $99.9 \pm 0.3$ & $99.4 \pm 0.2$ & $100.2 \pm 0.4$ \\
\hline Ketamine hydrochloride & $1,352 \pm 38.2$ & $101.8 \pm 0.7$ & $98.7 \pm 0.6$ & $102.0 \pm 1.9$ & $102.3 \pm 1.5$ & $99.8 \pm 0.5$ & $99.1 \pm 1.1$ \\
\hline Droperidol & $35.1 \pm 1.62$ & $99.8 \pm 0.9$ & $101.5 \pm 1.4$ & $99.5 \pm 0.3$ & $102.4 \pm 2.1$ & $98.8 \pm 1.0$ & $98.2 \pm 1.2$ \\
\hline
\end{tabular}

Note: ${ }^{\mathrm{a}} \mathrm{n}=3$.

Abbreviation: SD, standard deviation. 
Table 3 Stability of butorphanol tartrate, ketamine hydrochloride, and droperidol in $0.9 \%$ sodium chloride stored in polyolefin bags at $25^{\circ} \mathrm{C}$

\begin{tabular}{|c|c|c|c|c|c|c|c|}
\hline \multirow[t]{2}{*}{ Drug } & \multirow{2}{*}{$\begin{array}{l}\text { Initial } \\
\text { concentration }(\mu \mathrm{g} / \mathrm{mL})^{\mathrm{a}}\end{array}$} & \multicolumn{6}{|c|}{ Percentage initial concentration remaining ${ }^{a}($ mean $\pm S D)$} \\
\hline & & Day I & Day 3 & Day 5 & Day 7 & Day 10 & Day 14 \\
\hline Butorphanol tartrate & $67.0 \pm 0.80$ & $100.2 \pm 1.4$ & $99.7 \pm 1.2$ & $101.5 \pm 2.0$ & $101.2 \pm 1.1$ & $100.8 \pm 0.4$ & $99.2 \pm 1.6$ \\
\hline Ketamine hydrochloride & $1,395 \pm 83.2$ & $101.1 \pm 1.6$ & $100.2 \pm 1.7$ & $98.3 \pm 0.8$ & $99.1 \pm 0.4$ & $98.2 \pm 1.3$ & $98.7 \pm 0.5$ \\
\hline Droperidol & $34.3 \pm 1.91$ & $102.5 \pm 2.4$ & $98.7 \pm 1.4$ & $99.2 \pm 0.6$ & $101.0 \pm 1.2$ & $100.0 \pm 0.7$ & $101.9 \pm 0.9$ \\
\hline
\end{tabular}

Note: ${ }^{\mathrm{a}} \mathrm{n}=3$.

Abbreviation: SD, standard deviation.

the data presented herein and those from a previous study, it was believed that the ternary mixtures of butorphanol tartrate, ketamine hydrochloride, and droperidol in $0.9 \%$ sodium chloride infusion solutions were stable for up to 14 days when stored in polyolefin bags at either $4^{\circ} \mathrm{C}$ or $25^{\circ} \mathrm{C}$. The satisfactory stability of the drugs in the mixtures makes it possible to prepare them in advance by licensed central intravenous additive services, which may be convenient in hospitals.

\section{Conclusion}

The results obtained in our studies indicate that ternary mixtures of butorphanol tartrate $0.067 \mathrm{mg} / \mathrm{mL}$, ketamine hydrochloride $1.33 \mathrm{mg} / \mathrm{mL}$, and droperidol $0.033 \mathrm{mg} / \mathrm{mL}$ in $0.9 \%$ sodium chloride injection were stable for up to 14 days when stored in polyolefin bags at $4^{\circ} \mathrm{C}$ and $25^{\circ} \mathrm{C}$ and protected from light.

\section{Acknowledgments}

This work was supported in part by the Hubei Province health and family planning scientific research project (Numbers: WJ2015MB215 and WJ2015MB290) and Science and Technology Key Program of Shiyan (Number: 16Y66).

\section{Disclosure}

The authors report no conflicts of interest in this work.

\section{References}

1. Wang F, Shen X, Liu Y, Xu S, Guo X. Continuous infusion of butorphanol combined with intravenous morphine patient-controlled analgesia after total abdominal hysterectomy. A randomized, double-blind controlled trial. Eur J Anaesthesiol. 2009;26(1):28-34.

2. Thakore B, D’Mello J, Saksena S, Butani M. Comparison of fentanyl and butorphanol for postoperative pain relief with intravenous patient controlled analgesia. Acute Pain. 2009;11(3-4):93-99.

3. Kuo YM, Tsou MY, Chang WK, Chan KH, Chang KY. To add or not to add? An empirical study on droperidol and intravenous patient-controlled analgesia. J Chin Med Assoc. 2012;75(5):227-233.

4. Carstensen M, Møller AM. Adding ketamine to morphine for intravenous patient-controlled analgesia for acute postoperative pain. A qualitative review of randomized trials. Br J Anaesth. 2010;104(4):401-406.

5. Yamauchi M, Asano M, Watanabe M, Iwasaki S, Furuse S, Namiki A. Continuous low-dose ketamine improves the analgesic effects of fentanyl patient-controlled analgesia after cervical spine surgery. Anesth Analg. 2008;107(3):1041-1044.
6. Li YM, Deng FK. Effect of small dose ketamine on efficacy of PCIA with butorphanol after upper limbs surgery. Chin J Gen Pract. 2011; 9(5):705-707.

7. Gikic M, Di Paolo ER, Pannatier A, Cotting J. Evaluation of physicochemical incompatibilities during parenteral drug administration in a paediatric intensive care unit. Pharm World Sci. 2000;22(3):88-91.

8. Chen FC, Xiong H, Yang JG, Fang B, Zhu J, Zhou B. Butorphanol and ketamine combined in infusion solutions for patient-controlled analgesia administration: a long-term stability study. Med Sci Monit. 2015;21: 1138-1145.

9. Chen FC, Fang BX, Li P, Yang JG, Zhou BH. Compatibility of butorphanol and droperidol in $0.9 \%$ sodium chloride injection. Am J Health Syst Pharm. 2013;70(6):515-519.

10. Chandrakantan A, Glass PS. Multimodal therapies for postoperative nausea and vomiting, and pain. Br J Anaesth. 2011;107(Suppl 1): i27-i40.

11. Warren-Stomberg M, Brattwall M, Jakobsson JG. Non-opioid analgesics for pain management following ambulatory surgery: a review. Minerva Anestesiol. 2013;79(9):1077-1087.

12. Chen FC, Fang BX, Li P, Yang JG, Zhou BH. Study on the stability of butorphanol tartrate injection in $0.9 \%$ sodium chloride injection. Chin Pharm. 2012;15(11):1618-1620.

13. Donnelly RF. Stability of diluted ketamine packaged in glass vials. Can J Hosp Pharm. 2013;66(3):198.

14. Stucki MC, Fleury-Souverain S, Sautter AM, Sadeghipour F, Bonnabry P. Development of ready to use ketamine hydrochloride syringes for safe use in post-operative pain. Eur J Hosp Pharm Sci. 2008;14:14-18.

15. Gupta VD. Stability of ketamine hydrochloride injection after reconstitution in water for injection and storage in 1-mL tuberculin polypropylene syringes for pediatric use. Int J Pharm Compd. 2002;6: 316-317.

16. Desai A, Barkin RL, Doshi DH, Hanzel T, Dave U. Effect of elevated temperature and light on the stability of butorphanol tartrate. Am J Ther. 1999;6(2):91-95.

17. Ray JB, Newton DW, Nye MT, Leet WA. Droperidol stability in intravenous admixtures. Am J Hosp Pharm. 1983;40(1):94-97.

18. Chen FC, Fang BX, Li P, Zhu X, Zhou B. Physico-chemical stability of butorphanol-tramadol and butorphanol-fentanyl patientcontrolled analgesia infusion solutions over 168 hours. Pharmazie. 2014;69(8):585-588.

19. Chen FC, Xiong H, Liu HM, et al. Compatibility of butorphanol with granisetron in $0.9 \%$ sodium chloride injection packaged in glass bottles or polyolefin bags. Am J Health Syst Pharm. 2015;72(16): 1374-1378.

20. Chen FC, Shi XY, Li P, Yang JG, Zhou BH. Stability of butorphanoltropisetron mixtures in $0.9 \%$ sodium chloride injection for patientcontrolled analgesia use. Medicine. 2015;94(6):e432.

21. Parker WA. Compatibility of perphenazine and butorphanol admixtures. Can J Hosp Pharm. 1980;33:152.

22. Chen FC, Li P, Zhou BH, Fang B, Yang J. Stability of an epidural analgesic admixture containing butorphanol tartrate and ropivacaine hydrochloride. Eur J Hosp Pharm. 2015;22(1):7-11.

23. Fang BX, Zhu J, Chen FC, Fang B, Zhu J, Zhou B. Stability of butorphanol tartrate injection with lornoxicam injection in patient controlled analgesia pump. Cent South Pharm. 2013;11(10):732-734. 
24. Trissel LA, Saenz C, Williams YW, Ingram D. Incompatibilities of lansoprazole injection with other drugs during simulated Y-site coadministration. Int J Pharm Compd. 2001;5:314-321.

25. Gu JF, Qin WG, Chen FC, Xia Z. Long-term stability of tramadol and ketamine solutions for patient-controlled analgesia delivery. Med Sci Monit. 2015;21:2528-2534.

26. Lau MH, Hackman C, Morgan DJ. Compatibility of ketamine and morphine injections. Pain. 1998;75(2-3):389-390.

27. Roy JJ, Hildgen P. Stability of morphine-ketamine mixtures in $0.9 \%$ sodium chloride injection packaged in syringes, plastic bags and medication cassette reservoirs. Int J Pharm Compd. 2000;4(3):225-228.

28. Schmid R, Koren G, Klein J, Katz J. The stability of a ketaminemorphine solution. Anesth Analg. 2002;94(4):898-900.

29. Donnelly RF. Physical compatibility and chemical stability of ketaminemorphine mixtures in polypropylene syringes. Can J Hosp Pharm. 2009;62(1):28-33.

30. Walker SE, Law S, DeAngelis C. Stability and compatibility of hydromorphone and ketamine in normal saline. Can J Hosp Pharm. 2001;54: 191-199.

31. Ensom MH, Decarie D, Leung K, Montgomery C. Stability of hydromorphone-ketamine solutions in glass bottles, plastic syringes, and IV bags for pediatric use. Can J Hosp Pharm. 2009;62(2):112-118.

32. Ambados F, Brealey J. Compatibility of ketamine hydrochloride and fentanyl citrate in polypropylene syringes. Am J Health Syst Pharm. 2004;61(14):1438,1445.

33. Watson DG, Lin M, Morton A, Cable CG, McArthur DA. Compatibility and stability of dexamethasone sodium phosphate and ketamine hydrochloride subcutaneous infusions in polypropylene syringes. J Pain Symptom Manag. 2005;30(1):80-86.

34. Knudsen L, Eisend S, Haake N, et al. Physicochemical compatibility of commonly used analgesics and sedatives in the intensive care medicine. Eur J Hosp Pharm. 2014;21(3):161-166.
35. Donnely RF, Willman E, Andolfatto G. Stability of ketamine-propofol mixtures for procedural sedation and analgesia in the emergency department. Can J Hosp Pharm. 2008;61(6):426-430.

36. Stewart JT, Warren FW, King DT, Venkateshwaran TG, Fox JL. Stability of ondansetron hydrochloride and 12 medications in plastic syringes. Am J Health Syst Pharm. 1998;55(24):2630-2634.

37. Lebitasy M, Hecq JD, Vanbeckbergen D, Jamart J, Galanti L. Longterm stability of tramadol hydrochloride and droperidol mixture in 5\% dextrose infusion polyolefin bags at 5+/-3 degrees C. Ann Pharm Fr. 2009;67(4):272-277.

38. Williams OA, Middleton M, Henderson P, Reilly CS. Stability of morphine and droperidol separately and combined, for use as an infusion. Hosp Pharm Pract. 1992;2(9):597-600.

39. Lee DK, Wang DP, Harsono R, Wong CY. Compatibility of fentanyl citrate, ketamine hydrochloride, and droperidol in $0.9 \%$ sodium chloride injection stored in polyvinyl chloride bags. Am J Health Syst Pharm. 2005;62(11):1190-1192.

40. Selbach S, Diederich WE, Fett S, Fründ D, Koch T, Eberhart LH. Stability-indicating HPLC assays for the determination of piritramide and droperidol in PCA solution. J Clin Pharm Ther. 2011;36(2):161-165.

41. Trissel LA, Martinez JF. Compatibility of allopurinol sodium with selected drugs during simulated Y-site administration. Am J Hosp Pharm. 1994;51(14):1792-1799.

42. Trissel LA, Gilbert DL, Martinez JF. Incompatibility and compatibility of amphotericin B cholesteryl sulfate complex with selected other drugs during simulated Y-site administration. Hosp Pharm. 1998;33: 284-292.

43. Trissel LA, Saenz CA, Ogundele AB, Ingram DS. Physical compatibility of pemetrexed disodium with other drugs during simulated Y-site administration. Am J Health Syst Pharm. 2004;61(21):2289-2293.
Drug Design, Development and Therapy

\section{Publish your work in this journal}

Drug Design, Development and Therapy is an international, peerreviewed open-access journal that spans the spectrum of drug design and development through to clinical applications. Clinical outcomes, patient safety, and programs for the development and effective, safe, and sustained use of medicines are the features of the journal, which

\section{Dovepress}

has also been accepted for indexing on PubMed Central. The manuscript management system is completely online and includes a very quick and fair peer-review system, which is all easy to use. Visit http://www.dovepress.com/testimonials.php to read real quotes from published authors. 